\title{
International research could ease world food problem
}

Future research carried out by the Consultative Group on International Agricultural Research (CGIAR) could help lower the probability of extreme food shortages and stabilise international food markets. This could be achieved if food importing countries, whether developing or industrialised, applied new research results to increase their own food output and lessen their reliance on world food markets; and if exporters did the same to increase the food available to importers.

These are the conclusions of a report published last week called 'International agricultural research: potential impact on world food markets and UK agricultural strategy'. It was produced for the Centre for Agricultural Strategy at Reading University by A F McCalla of the University of California, who is researching into the efiects of the CGIAR research programme on world food supplies.

Before drawing his conclusions, Dr McCalla is careful to point out that research is only one factor influencing world food output and that the CGIAR programme is only a small aspect of that research. In 1974, he says, an estimated $\$ 3.8$ billion was spent on agricultural research throughout the world. The developing countries accounted for $15 \%$ or $\$ 0.57$ billion of this expenditure, of which $\$ 50$ million or $10 \%$ was spent by the CGIAR. The CGIAR was therefore responsible for no more than $2 \%$ of the total world expenditure on agricultural research.
The CGIAR was set up in 1971 by the UN Food and Agriculture Organisation, the World Bank and the United Nations Development Programme to work towards increasing food production in the developing world by supporting agricultural research and training. It runs nine international centres, most of them concerned with crop research. Some concentrate on specific commodities such as cereals, rice and potatoes; some work on the problems of a specific ecological zone or region, such as dry areas or semi-arid tropics; and some work in the problems of a particular region such as specific livestock diseases in Africa.

The interests of the CGIAR reflect the results of studies quoted in the Ieport which suggest that the world food problem is concentrated in the developing world, where the increase in population is outstripping any increase in food output, and that it is mainly one of crop production. According to one study quoted by Dr McCalla, $90 \%$ of the food energy eaten in developing countries comes from plants, $9 \%$ from animals and $1 \%$ from fish. Most of the plants eaten are cereals-wheat, rice, sorghum and millet-and potatoes, cassava and yams. Cereals are estimated to contribute $50-70 \%$ of total food energy.

There are two possible ways of easing the food problem of the developing countries, says $\mathrm{Dr}$ McCalla. Either they increase their food pro- duction or there is an increase in the international trade of foodstuffs between them and the industrialised world. The former should improve food balances, but the latter might make matters worse.

In 1970, the world output of plant products was estimated at 3146 million tonnes of which 1208 million tonnes was cereals, accounting for $60 \%$ of total food energy and $73.5 \%$ of the world crop area. Trade in agricultural products, however, only amounted to $7 \%$ of global production, more than $50 \%$ being in cereals. A look at the origin and destination of trade shows that more than $75 \%$ of the volume of exports comes from developed countries and $80 \%$ goes to them.

Developing countries should, therefore, strive to increase their own food output. And the CGIAR research programmes, Dr McCalla concludes, might help them go some way towards achieving this. Based on four 'hazardous judgements'-the length of time a CGIAR centre has been open, the amount of research done on the commodity prior to the opening, the complexity of the research mandate of the centre and the imminence of important research results as anticipated by research workers-he estimates the likelihood of obtaining output increasing research within five to ten years (see table). The most promising crops appear to be maize and triticale, both under study in Mexico.

Judy Redfearn

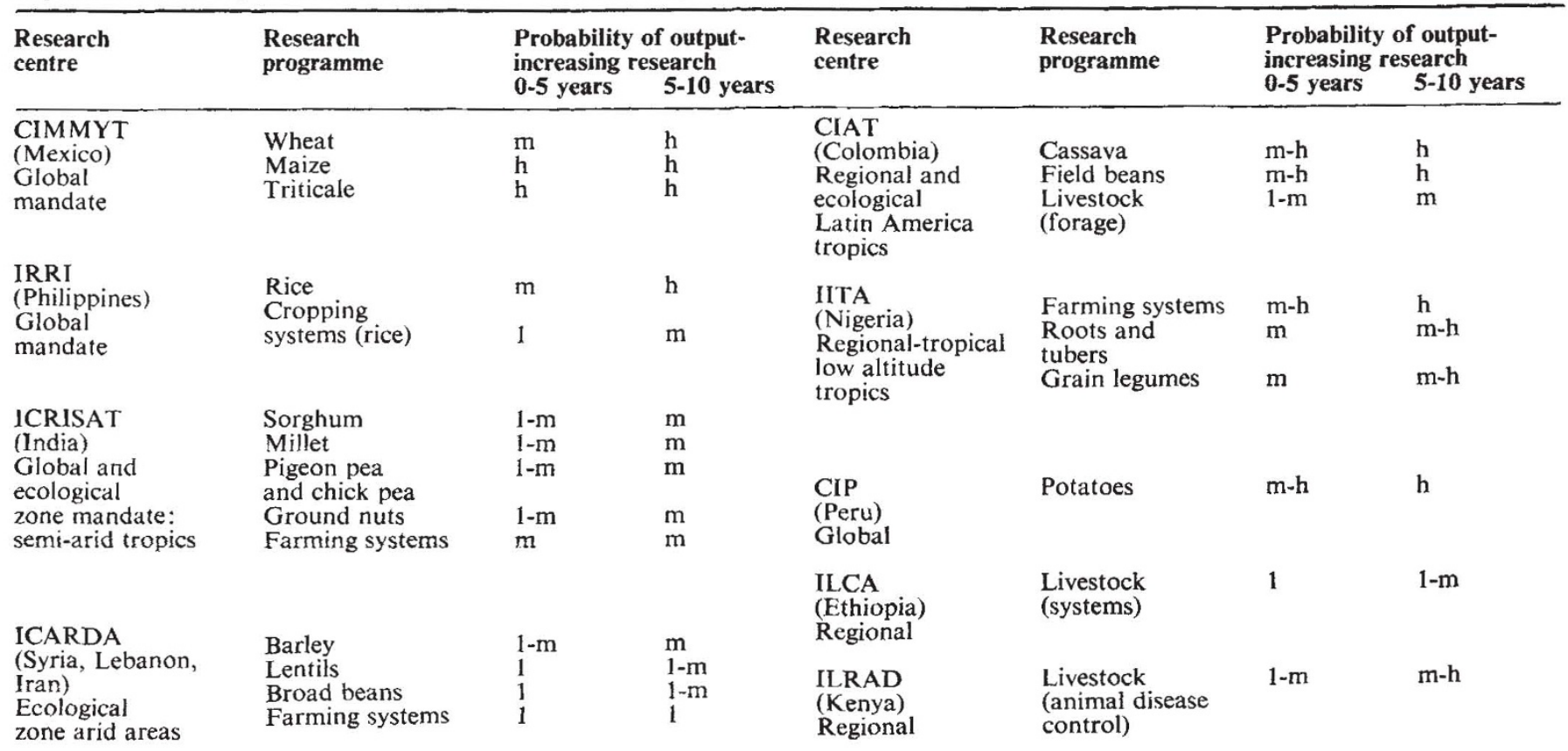

1--low m-medium h--high

CIAT-Centro Internacional de Agricultura Tropical CIMMYT-Centro Internacional de Mejoramiento de Maiz y Trigo CIP_-Centro Internacional de la Papa ICARDA-International Centre for Agricultural Research in the Dry Areas ICRISAT-International Crops Research Institute IITA-International Institute of Tropical Agriculture ILCA--International Livestock Centre for Africa ILRADInternational Laboratory for Research on Animal Diseases IRRI--International Rice Research Institute. 